(C2018, Elsevier. Licensed under the Creative Commons Attribution-NonCommercialNoDerivatives 4.0 International http://creativecommons.org/about/downloads

cc) $(1) \Theta$ 


\section{A Note on the Role of Energy in Production}

Steve Keen, Kingston University London (corresponding author: debunking@gmail.com)

Robert U. Ayres, INSEAD, France

Russell Standish, Kingston University London

\section{Abstract}

Energy plays no role in the standard Cobb-Douglas Production Function (CDPF), and a trivial role in a three-factor CDPF where it is treated as a third input, independent of labour and capital. Starting from an epistemological perspective, we treat energy as an input to both labour and capital, without which production is impossible. We then derive an energy-based CPDF (EBCDPF) in which energy plays a critical role. We argue for the redefinition and measurement of real GDP in terms of exergy. We conclude that the "Solow Residual" measures the contribution of exergy to growth, and that the exponents in the EBCDPF should be based on cross-country comparative data as suggested by Mankiw (1995) rather than the "cost-share theorem", resulting in a much higher role for exergy and capital in growth and a correspondingly lower role for labour.

\section{Introduction}

The purpose of this paper is to provide an aggregate production function - that is, a function relating a single measure of output $(\mathrm{Q})$ to single inputs of Labour $(\mathrm{L})$, Capital $(\mathrm{K})$ and Energy $(\mathrm{E})$-in which energy plays an essential role, and to follow through the consequences of this function at the level of aggregate inputs and output.

By "an essential role", we mean incorporating energy in a way in which its role in production is neither trivial, nor reducible to zero via a suitable choice of parameters, and which is also compatible with the Laws of Thermodynamics. This is the not case with, to our knowledge, all attempts to incorporate energy in production functions to date, which have, either in their derivation or their final form, shared the strategy of replacing a function of the form:

$$
Q=F(L, K)
$$

with a function of the form:

$$
Q=F(L, K, E)
$$

The Neoclassical Cobb-Douglas Production Function (Cobb and Douglas 1928) is based on Equation (1.1):

$$
Q=A \cdot K^{\alpha} \cdot L^{\beta}
$$

Here A represents "total factor productivity". The sensible assumption of constant returns to scale (a doubling of all inputs with unchanged technology should result in a doubling of output) imposes a well-known constraint on the exponents:

$$
\alpha+\beta=1
$$

When Equation (1.2) is applied, the modified Cobb-Douglas Production function with energy is: 


$$
Q=A \cdot K^{\alpha} \cdot L^{\beta} \cdot E^{\chi}
$$

as in (Solow 1974, p. 34, Stiglitz 1974, Equation 1, p. 141, Kümmel, Ayres et al. 2010, Equation 50, p. 166). ${ }^{1}$ The condition of constant returns to scale is now that:

$$
\alpha+\beta+\chi=1
$$

We call Equation (1.5) the Energy-Augmented Cobb-Douglas Production Function (EACDPF).

Energy plays a non-essential role in this equation. If we choose values for $\boldsymbol{\alpha}$ and $\boldsymbol{\beta}$ such that $\alpha+\beta=1$, then this eliminates any role for energy in production, and makes (1.5) equivalent to the standard CDPF, which predicts non-zero output for zero energy input.

When the choice of a value for $\chi$ is guided by the "cost-share theorem", based on the expenditure on energy as a percentage of GDP, so that $\chi \approx 0.07,{ }^{2}$ the role for energy is still trivial. With representative values for $\alpha$ of 0.3 and therefore for $\beta$ of 0.63 , Equation (1.5) implies that a $50 \%$ increase in energy input (while holding $L$ and $K$ constant) would cause only a $3 \%$ increase in output. Similarly, it implies that a substantial fall in energy input-say a $10 \%$ fall below current levels-would cause only a $0.7 \%$ fall in output. Extreme falls in energy input also have trivial effects: a $90 \%$ fall in energy input would cause only a $15 \%$ fall in output; even a $99 \%$ fall in energy input would cause only a $28 \%$ fall in output.

The same is not the case for the other inputs $L$ and K. Given the same values for $\alpha$ and $\beta$, Equation (1.5) suggests that changes in Capital have substantially larger impacts on output than changes in Energy, while changes in Labour have the greatest impact. The impact of changes in labour inputs is quasi-linear: a $50 \%$ increase in Labour inputs causes a $29 \%$ increase in output, while a $50 \%$ fall in labour results in a $35 \%$ fall in Q. Changes in capital have a significantly less than linear but still substantial impact on production: a $50 \%$ increase in capital causes an $13 \%$ increase in output, while a $50 \%$ fall in capital causes a $19 \%$ fall in Q (see Figure 1 ).

While in practice such large changes in energy without changes in labour and capital are not feasible, the relatively trivial impact on output of changes in energy compared to changes in labour and capital in this model fails Solow's "smell test" (Solow 2010, p. 12): something must be wrong with expressing energy's role this way.

\footnotetext{
${ }^{1}$ The Stiglitz and Solow papers use R for "exhaustible natural resources", which can be interpreted as a proxy for energy. The Kummel paper uses dimensionless values for $Q, L, K$ and $E$.

${ }^{2}$ See columns 6 and 8 in https://www.eia.gov/totalenergy/data/annual/pdf/sec1_13.pdf.
} 


\section{Output Level Given Change in Factor Input, Energy-Augmented CDPF}

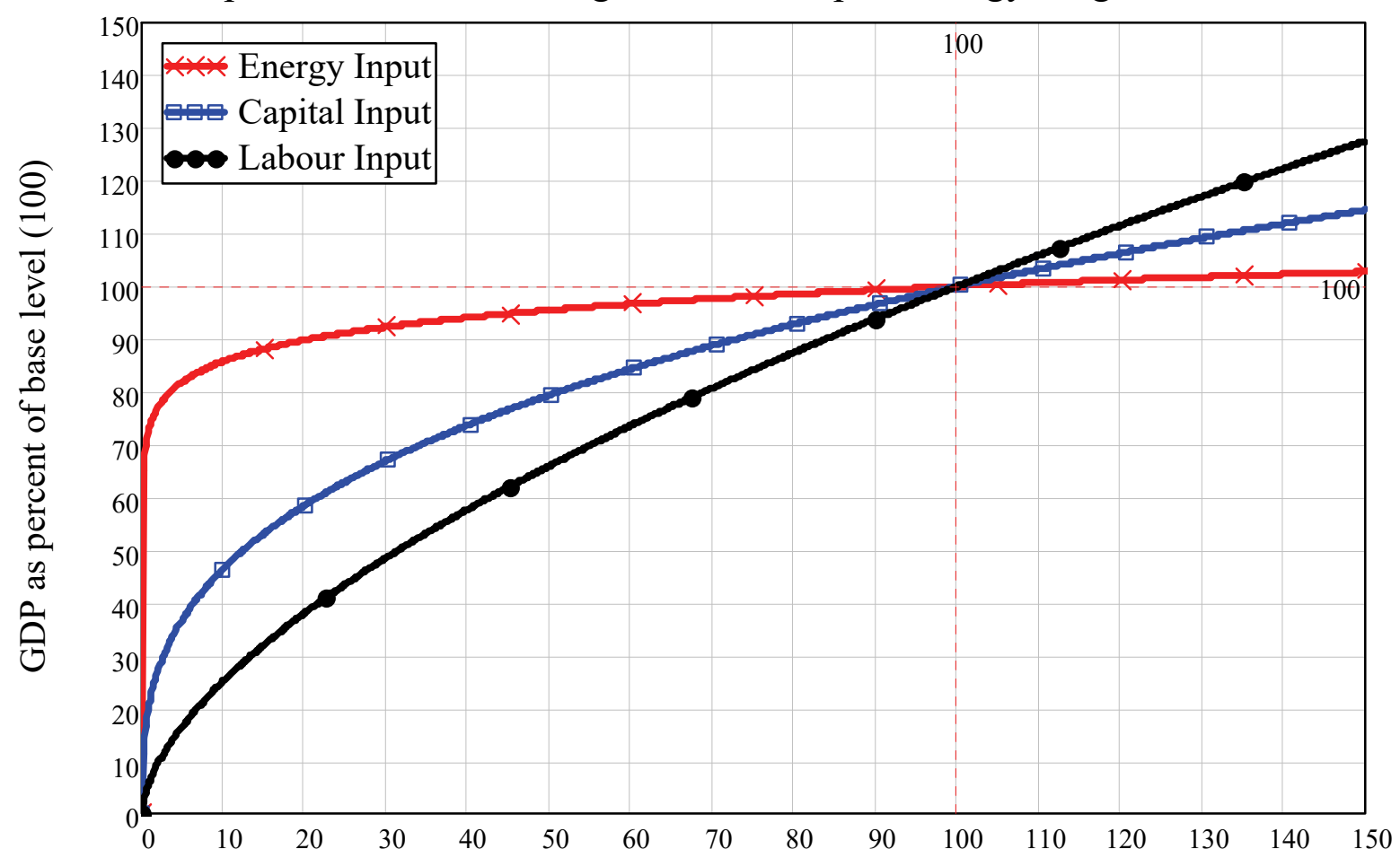

Percent of input compared to base level (100)

\section{Methodology}

The alternative approach we propose to Equation (1.2) is to treat energy, not as an independent input to production on the same footing as labour and capital, but as an input to both labour and capital that enables them to produce output:

$$
Q=F(L(E), K(E))
$$

This altered form is motivated by epistemological concerns, as well as the empirical issues already outlined. The functional form shown in Equation (1.2) implies that energy can be added to a production process independently of labour and capital, and that labour and capital can operate without energy inputs themselves. Neither proposition is true. Adding energy independently of labour and capital to a production process would cause not output but destruction: both labour and capital are needed, and are used, to harness energy in its various forms to perform useful work. Similarly, both labour and capital need energy in order to be able to function: to coin a phrase, labour without energy is a corpse, while capital without energy is a sculpture.

The functional form in Equation (1.7) acknowledges both epistemological issues: energy is not added to a production process independently of labour and capital, but is instead channelled by them to perform useful work; and if the energy input to either labour or capital is zero, then the useful work performed by it is also zero.

Once both labour and capital are seen as means to turn energy into useful work, then the inputs of the functions $L(E)$ and $K(E)$ are energy, while the outputs are the potential for useful work (exergy). Functional forms that meet the requirements of having energy as the inputs to labour and capital 
(while not yet improving upon the poorly-specified nature of the definitions of $L$ and $K$ in existing production functions) and exergy as the outputs are:

$$
L(E)=L \cdot E_{L} \cdot \frac{E_{X}{ }^{L}}{E_{L}}=L \cdot E_{L} \cdot e_{X}{ }^{L}
$$

and

$$
K(E)=K \cdot E_{K} \cdot \frac{E_{X}{ }^{K}}{E_{K}}=K \cdot E_{K} \cdot e_{x}{ }^{K}
$$

Here $L$ and $K$ respectively have the same meanings as in the standard Cobb-Douglas production function: the number of employed-workers-hours per year, and a poorly defined and contested (Sraffa 1960, Samuelson 1966, Robinson 1971, Harcourt 1972, Pasinetti, Fisher et al. 2003) concept of the number of units of homogeneous machinery; $E_{L}$ and $E_{K}$ indicate the aggregate energy consumption per worker and per "representative machine" per year respectively; and $e_{x}{ }^{L}$ and $e_{x}{ }^{K}$ represent the efficiency with which these energy inputs are converted into the potential for useful work (exergy).

This epistemologically correct way of stating energy's role in production raises several issues about the definitions and measurements of the inputs of energy to labour and capital, their outputs, and the definition of output itself.

The measurements of $L, E_{L}$ and $e_{x}{ }^{L}$ are all independently problematic.

Firstly, should L represent all employed workers (which has been the standard approach in the use of production functions), or only those directly or indirectly involved in production of goods and services? Should $L$ be weighted for skill levels?

Since the purpose of this paper is to develop stylized production functions for economic modelling with a realistic role for energy, in place of existing stylized production functions which ignore or underestimate the role of energy, we choose to not address the labour-definition issue at this time. We therefore continue with the standard practice of using $L$ to represent the entire workforce. We also abstract from the distinction between skilled and unskilled labour to treat $L$ as representing unskilled labour only. By unskilled we do not mean uneducated, but sufficiently educated to be able to be instructed on how to operate or work with the relevant machinery $(K)$ at any point in time to produce output. $^{3}$

Secondly, what measure of $E_{L}$ should be used: the actual average energy consumption per worker at any given point in time, or the energy necessary for a worker to undertake labour of average skill at all points in time? Should the measure $E_{L}$ be somehow altered to accommodate for rising skill levels over time? Lastly, how is $e_{x}{ }^{L}$ to be determined?

\footnotetext{
${ }^{3}$ Though the level of knowledge embodied in today's manufacturing technology is far greater than in the past and has clearly risen over time since the Industrial Revolution, the level of knowledge needed to operate that machinery as an unskilled worker has not necessarily risen. An $18^{\text {th }}$ century spindle worker arguably needed more knowledge of how a spindle operates than a textile worker needs today to control the spindle's successor.
} 
We circumvent these issues by noting that the product $E_{L} \cdot e_{x}{ }^{L}$ is equivalent to the actual exergy performed by a labourer, and treat this product as a constant:

$$
E_{L}(t) \cdot e_{x}{ }^{L}(t)=E_{x}{ }^{L}=\text { constant }
$$

We justify this simplifying assumption as follows.

The energy consumed per head of population in the USA has risen fifteen-fold since 1650 (see Figure 2).$^{4}$ On this basis, the amount of energy imparted to production by workers could also be said to have risen dramatically.

Figure 2: US Population and energy growth and energy per capita since 1650

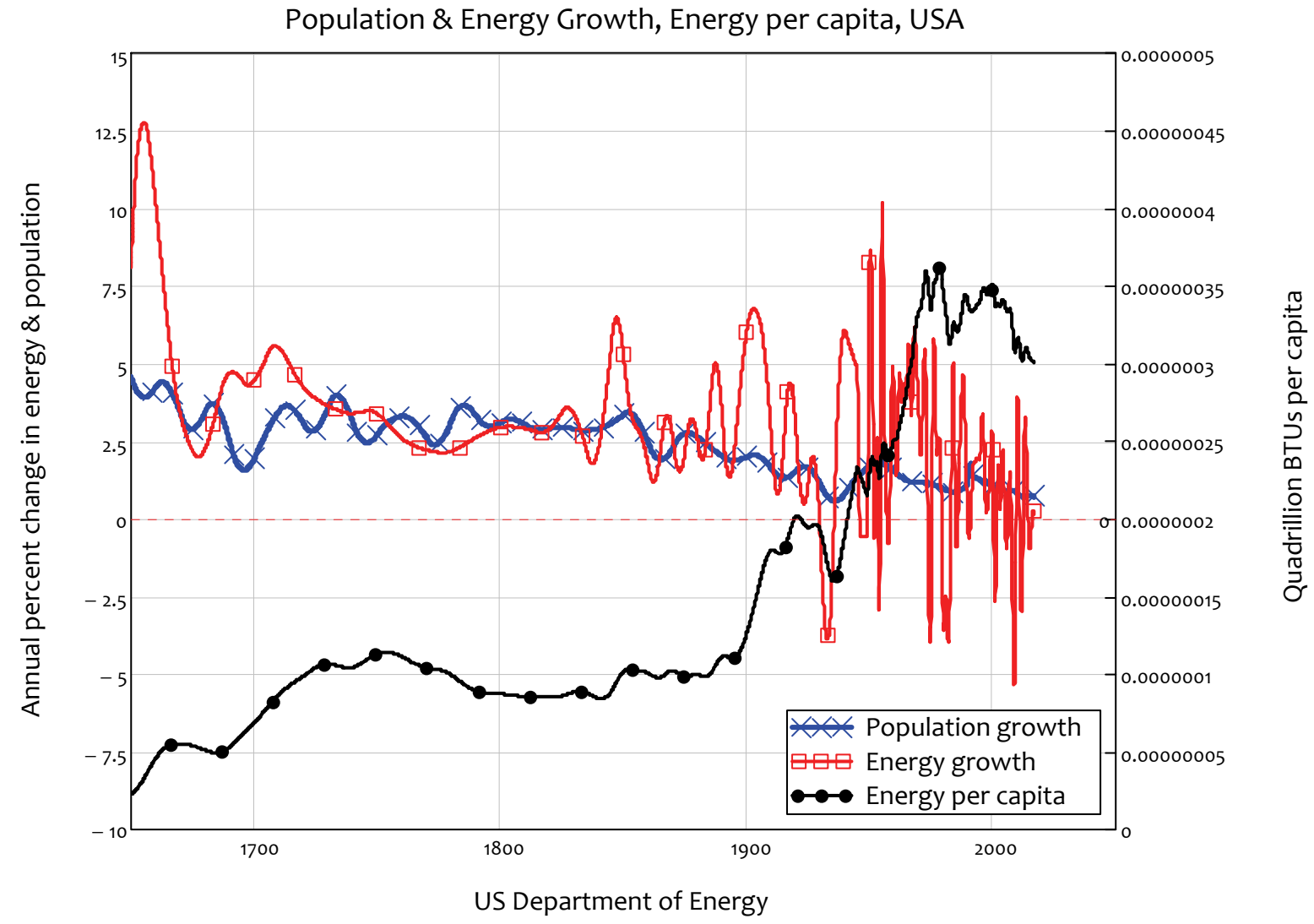

However, though the energy consumption of the average worker has risen, the amount of energy required of the worker to control the relevant tools has changed little, if only because human capacity to do useful work has not changed. Over the same period, the actual energy input needed per worker to do useful work has quite possibly has fallen in many industries, since the use of machines which enable the direct conversion of human energy into useful work has progressively

\footnotetext{
${ }^{4}$ Energy data comes from https://www.eia.gov/totalenergy/data/annual/pdf/aer.pdf and https://www.eia.gov/totalenergy/data/monthly/pdf/sec13 21.pdf
} 
been replaced by the control of machines which have their own independent sources of energy. The sledgehammer has been supplanted by the jackhammer. The amount of exergy imparted by the unskilled operator to control the jackhammer is, in all likelihood, lower than that imparted by his ancestor (or underdeveloped economy equivalent) to wield the sledgehammer, but the amount of exergy imparted by the tool has increased dramatically. ${ }^{5}$

Of course, neither the sledgehammer nor the jackhammer could do anything without the labourers wielding them, but in the end what the labourers are doing is using their intelligence to direct some of their exergy into performing useful work in construction. We argue therefore that the worker's contribution to production is the intelligent application of exergy to control a machine, to impart exergy to a machine, or to perform a function that the machine itself cannot do, where the exergy per worker $E_{x}{ }^{L}$ has not changed over time. ${ }^{6}$ We therefore reduce Equation (1.8) to:

$$
L(E)=L(t) \cdot E_{x}{ }^{L}
$$

The issues involved in defining and measuring $K$ have been well explored (Sraffa 1960, Samuelson 1966, Robinson 1971, Harcourt 1972, Pasinetti, Fisher et al. 2003), though their implications for aggregate production functions, and especially for the marginal productivity theory of income distribution, are not well appreciated. We will not consider these implications here, and continue with the concept of $K$ as representing an aggregate measure of the physical capital of an economy.

Since $K$ is a poorly defined quantity, so too are the concepts of $E_{K}$, the energy consumed per year per "representative machine", and the exergy ratio $e_{x}{ }^{K}$ of that machine. However, the product $K \cdot E_{K}$ is the aggregate amount of energy consumed by industry per year, which is both well-defined and accurately measured by a number of agencies. ${ }^{7}$ It is thus possible to replace $K \cdot E_{K}$ with a welldefined product $E^{\Sigma K}$, which represents the total energy consumed in industry:

$$
E^{\Sigma \kappa}=K \cdot E_{K}
$$

That leaves the estimation of $e_{x}{ }^{k}$. This cannot be measured per representative machine without a valid means of deriving a value for $K$, but since the pioneering work of Ayres, Ayres and Warr (2003),

\footnotetext{
${ }^{5}$ This example is one where the skill needed to operate the machine has risen over time, but frequently, where the worker imparts exergy directly to a production process today, the input is often menial compared to the work of previous generations of unskilled workers, as a recent New York Times article indicated: "“'They're paying you to do a job," she added. "They're not paying you to be happy." Her work is physically exhausting yet precise. Standing on her feet for the entire shift, Ms. Hargrove inserts tweezer-like strips of metal thousands of times a day into a tube that forms part of the heat exchanger in each furnace." "At Carrier, the Factory Trump Saved, Morale Is Through the Floor", New York Times August 10, 2018:

https://www.nytimes.com/2018/08/10/business/economy/carrier-trump-absenteeism-morale.html). ${ }^{6}$ As the example in footnote 5 implies, in today's highly mechanized factories, many of the tasks that remain for humans to perform exist because they are too minor in scale to justify designing a specific machine to perform them instead. Great skill is required for design, control and maintenance of advanced machinery, but only the trainable flexibility that average human intelligence imparts is necessary for the performance of routine assembly tasks.

${ }^{7}$ See https://www.eia.gov/totalenergy/data/browser/xls.php?tbl=T02.01\&freq=m for US monthly data broken down by sector, and https://vearbook.enerdata.net/ for privately collected but publicly accessible yearly data on energy production by source and aggregate consumption for over 40 countries. The International Energy Agency IEA provides for-fee national and sectoral data at https://webstore.iea.org/world-energy-balances2017. The UN has for-fee and free after a time lag data at https://unstats.un.org/unsd/energy/yearbook/default.htm.
} 
a number of researchers have calculated the energy to exergy ratios for many industrial processes, from which an aggregate measure of exergy $E_{x}{ }^{2 \kappa}$ has been calculated (Ayres, Ayres et al. 2003, Figure 17, p. 243), and from which an aggregate measure of the exergy/energy ratio $e_{x}^{\Sigma \kappa}$ can been derived (Ayres and Warr 2005, Warr, Ayres et al. 2010, Ayres and Voudouris 2014, Santos, Domingos et al. 2018). ${ }^{8}$

Four variants of Equation (1.9) are therefore feasible, depending on the issue being considered:

$$
\begin{aligned}
K(E) & =K \cdot E_{K} \cdot e_{x}^{K} \\
& =K \cdot E_{X}{ }^{K} \\
& =E^{\Sigma K} \cdot e_{x}^{\Sigma K} \\
& =E_{X}{ }^{\Sigma K}
\end{aligned}
$$

The first and second forms are applicable to macroeconomic modelling, since the level of installed capital depends upon past investment decisions, the energy throughput at a point in time depends upon technology at the time and aggregate demand, and the efficiency with which energy is converted into exergy depends upon technology and the relative cost of energy. These distinctions are lost in the third and fourth forms, but $E^{\Sigma K}, e_{x}^{\Sigma K}, E_{X}{ }^{\Sigma K}$ are capable of measurement, whereas $K$ (and therefore $E_{K}, E_{x}{ }^{k}$ and $e_{x}{ }^{k}$ ) is not. However, for modelling purposes it is useful (depending upon the issue being examined) to make distinctions between the stock of machines, the average energy throughput of those machines, and the efficiency with which those machines transform energy into useful work.

If the impact of variations in the cost of energy are being considered (both in terms of relative price and EROEI), or the phenomenon of the decline in the energy intensity of economic growth at high levels of development (Smil 2017, Box 6.10) then the first form is preferable, with the plausible assumptions that the energy throughout of the representative machine has normally been growing over time, but is negatively affected by the price of energy, while its exergy to energy ratio is positively affected, but bounded between greater than 0 and less than 1 :

$$
\begin{aligned}
K(E) & =K(t) \cdot E_{K}(t) \cdot e_{x}{ }^{K}(t) \\
E_{K}(t) & =E_{K}(0) \cdot e^{\varepsilon \cdot t} \\
0 & <e_{x}{ }^{K}(t)<1
\end{aligned}
$$

If just the relationship between inputs to production and outputs are being considered, then the second form is preferable, combined with the simplifying assumption that the exergy output $E_{X}{ }^{k}$ of the "representative machine" has been growing exponentially over time:

$$
E_{X}{ }^{K}(t)=E_{X}{ }^{K}(0) \cdot e^{\varepsilon_{x} \cdot t}
$$

\footnotetext{
${ }^{8}$ There are also some online databases; see f(1.19)or example https://tntcat.iiasa.ac.at/PFUDB/dsd.

${ }^{9}$ Here $E_{K}(0)$ represents the energy input to a representative machine at a specified initial time 0 (which can be any arbitrary time in the past).

${ }^{10}$ Here $E_{X}{ }^{K}(0)$ represents the exergy output of a representative machine at a specified initial time 0 (which can be any arbitrary time in the past).
} 
Since we are considering the basic aggregate production function in this paper, we reduce Equation (1.9) to:

$$
K(E)=K(t) \cdot E_{X}{ }^{K}(t)
$$

Our final and perhaps most controversial redefinition is that of $Q$ (GDP). We argue that, with the inputs to the production function being exergy, the output should also be exergy: real GDP should be measured in terms of useful work. In keeping with our practice above, this should have two components: the total energy harnessed to generate $\operatorname{GDP}\left(E^{\operatorname{CDP}}\right)$, and the efficiency with which this energy is converted into useful work $\left(e_{X}{ }^{G D P}=E_{X}{ }^{G D P} / E^{G D P}\right)$

$$
\begin{aligned}
Q & =E^{G D P} \cdot \frac{E_{X}^{G D P}}{E^{G D P}} \\
& =E^{G D P} \cdot e_{X}^{G D P}
\end{aligned}
$$

This is obviously not current practice. Since its inception as an economic concept, real GDP has instead been estimated by summing up monetary transactions (and cross-checking the sums via the expenditure, income and production methods) and deflating nominal values by indices (Laspeyres or Paasche) to account for price changes over time. Also, virtually from its inception, the concept and measurement of GDP have been controversial. Yet it survives in what van den Burgh aptly describes as "The GDP paradox":
For over half a century now, the GDP (per capita) has been severely criticized as not adequately capturing human welfare and progress. All the same, the GDP has maintained a firm position as a dominant economic indicator, which can be regarded as a paradox ... To resolve the paradox, or explain its persistence, one has to recognize the ambivalence with which many academic economists approach the criticism of the GDP indicator: they accept it but deny its relevance. (Bergh 2009, p. 118)

It would be a radical departure from current practice to measure GDP in terms of exergy. But we believe that, not only is this redefinition consistent with acknowledging the crucial role of energy in production, it also provides a solid basis on which many of the criticisms of the concept and measurement of GDP could be addressed. Van den Burgh summarizes these under five headings: "Principles of proper accounting... Intertemporal considerations... Lexicographic preferences... Empirical studies of happiness... Income distribution, relative income and rivalry for status" (Bergh 2009, pp. 118-120). Measuring GDP in terms of exergy would address the first three shortcomings directly:

- A definition of GDP in terms of exergy inherently distinguishes between benefits and costs. For example, in the transportation component of GDP, the actual service is the movement of a specific mass from one location to another in a specified time, the minimum energy costs of which can be calculated. Fuel wasted by traffic congestion, ambulance and medical costs from road accidents, and so on, which are added to GDP as currently measured, would reduce the ratio $e_{x}{ }^{G D P}$, thus reducing an exergy-based measure of GDP, by increasing the actual energy used to deliver transportation services, without increasing transportation itself;

- Specifying GDP in terms of exergy gives a direct quantitative means to compare past levels of consumption to today's, and the use of exergy as opposed to energy also accounts for changes in energy efficiency as well; and 
- Though we do not explore this issue here given our focus on aggregate production functions, specifying GDP in terms of exergy implies the capacity to estimate GDP as the scalar representation of the primary forms in which exergy is consumed-food, shelter, transportation, etc. This implies the capacity to supplement the aggregate measure with disaggregation in terms of basic needs.

We do not expect our exergy definition of GDP to be adopted, any more than have previous attempts to produce alternative aggregate indices. But we believe that it is valid to treat real GDP as aggregate exergy in economic modelling, and we proceed on this basis.

\section{Results}

Applying the foregoing to the basic CDPF, we combine Equations (1.11) and (1.16) to yield what we call the Energy-Based Cobb-Douglas Production Function (EBCDPF):

$$
Q(t)=\left(K(t) \cdot E_{x}{ }^{K}(t)\right)^{\alpha} \cdot\left(L(t) \cdot E_{x}{ }^{L}\right)^{\beta}
$$

This epistemologically accurate way of accounting for the role of energy in production presents several challenges to the conventional interpretation of the coefficients $\alpha$ and $\beta$ as representing both the marginal products and the rates of return to capital and labour respectively, with the former being of the order of 0.33 and the latter 0.67 .

Firstly, Equation (1.18) can be reworked to isolate the labour and capital components of the conventional CDPF. Substituting $C$ for the constant $\left(E_{x}{ }^{L}\right)^{\beta}$ and dropping time notation for simplicity, we write:

$$
Q=C \cdot\left(E_{x}{ }^{K}\right)^{\alpha} \cdot K^{\alpha} \cdot L^{\beta}
$$

Equation (1.19) therefore identifies the "total factor productivity" term in the standard CDPF (Equation (1.3)) as in fact the contribution of exergy to production, where only the exergy of capital has a time trend:

$$
A=C \cdot\left(E_{x}{ }^{k}\right)^{\alpha}
$$

Equation (1.20) indicates that the "Solow Residual" measures the contribution to growth of the exergy of the "representative machine". It is not a residual, but result of the original Cobb-Douglas production function being poorly specified by not considering the role of energy.

Secondly, Equation (1.18) isolates the exergy contributions of machinery and labour respectively, where the former is orders of magnitude greater than the latter:

$$
Q=\left(K \cdot E_{x}{ }^{K}\right)^{\alpha} \cdot\left(L \cdot E_{x}{ }^{L}\right)^{\beta}
$$

The fact that the much smaller exergy contribution of labour has a much higher exponent than the much larger contribution of machinery again raises Solow's "smell test": something must be wrong with attributing such a large causal role to the much smaller exergy contribution.

\footnotetext{
${ }^{11}$ Where $E_{X}{ }^{K}(t)=E_{X}{ }^{K}(0) \cdot e^{\varepsilon_{X} \cdot t}$. We initially dispense with the A term, which was originally introduced for data fitting purposes (Cobb and Douglas 1928, p. 152).
} 
One of the key appeals of the Cobb-Douglas Production Function has always been that it appears to be consistent with the marginal productivity theory of income distribution. However, as Mankiw points out, these income-distribution-based exponents lead to a number of empirical problems for Neoclassical growth theory in general, and the Cobb-Douglas Production Function in particular. These are that, if the exponents for labour and capital are $2 / 3^{\text {rds }}$ and $1 / 3^{\text {rd }}$ respectively, then Neoclassical growth theory in general, and the standard Cobb-Douglas Production Function without energy in particular:

can explain [national per capita] incomes that vary by a multiple of slightly more than two. Yet income per person varies by a multiple of more than ten. There is much more disparity in international living standards than the neoclassical model predicts...

the model predicts convergence [of GDP per capita] at about twice the rate that actually occurs;

the return to capital moves proportionately twice as much (in the opposite direction) as the level of income. Because poor countries have about one-tenth the income of rich countries, they should have returns to capital that are about one hundred times as large. In particular, since the profit rate is about 10 percent per year in rich countries, it should be about 1,000 percent per year in poor countries..... For the traditional Cobb-Douglas production function, the return differentials predicted by the neoclassical model are vastly larger than are observed in the world. (Mankiw, Phelps et al. 1995, pp. 283-289)

Mankiw then notes that all these problems stem from the coefficient for capital $\alpha$ being $1 / 3^{\text {rd }}$, and that if the coefficient were instead $2 / 3^{\text {rds }}$ then all of these empirical problems would disappear:

Suppose, however, that the capital share were two-thirds rather than one-third... If one country has four times the saving rate as another, it would have sixteen times as much income per person, rather than only two times as much. Thus, the model can now explain variation in income of the magnitude observed... the model now predicts the rate of convergence estimated in the empirical literature... the predicted return differential falls from a multiple of 100 to a multiple of 3.16... (Mankiw, Phelps et al. 1995, pp. 290-292)

Mankiw then suggests an externalities explanation for the return to capital for a society being twice as high as that measured for individual capitalist income (Mankiw, Phelps et al. 1995, pp. 292-293). The extensive literature showing that the Cobb-Douglas Production Function is simply a reworking of the income distribution identity that wages plus profits equals GDP under conditions of relative stability in that distribution (Shaikh 1974, Shaikh 1987, McCombie 2000, Felipe and Adams 2005, Felipe and McCombie 2007) provides another reason to ignore that empirically meaningless result, and to treat Mankiw's empirical inter-country guidelines for the value of $\alpha$ as worthy of consideration. This implies the following form for an empirically grounded, energy-based CobbDouglas Production Function:

$$
\mathrm{Q}=\mathrm{C} \cdot\left(\mathrm{E}_{\mathrm{X}}{ }^{\mathrm{K}}\right)^{\alpha} \cdot \mathrm{K}^{\alpha} \cdot \mathrm{L}^{1-\alpha}, \alpha=2 / 3
$$

With these values, the marginal impact of varying either the exergy per machine, or the number of machines, is very close to linear: a $1 \%$ increase in either causes a $0.67 \%$ increase output, versus a $0.33 \%$ increase in output for a $1 \%$ increase in labour; a $40 \%$ fall in either capital or exergy per unit of capital causes a $30 \%$ fall in output (see Figure 3 ). That the impact of varying exergy per machine- 
which in practical terms can equate to running production lines faster with a constant number of workers per line-is roughly linear, does we believe pass Solow's smell test.

Figure 3: Relative impact of changes in factor inputs on output in the Energy-Based Cobb-Douglas Production Function with constant returns to scale and cross-country growth-consistent coefficients.

Output Level Given Change in Factor Input, Energy-Based CDPF

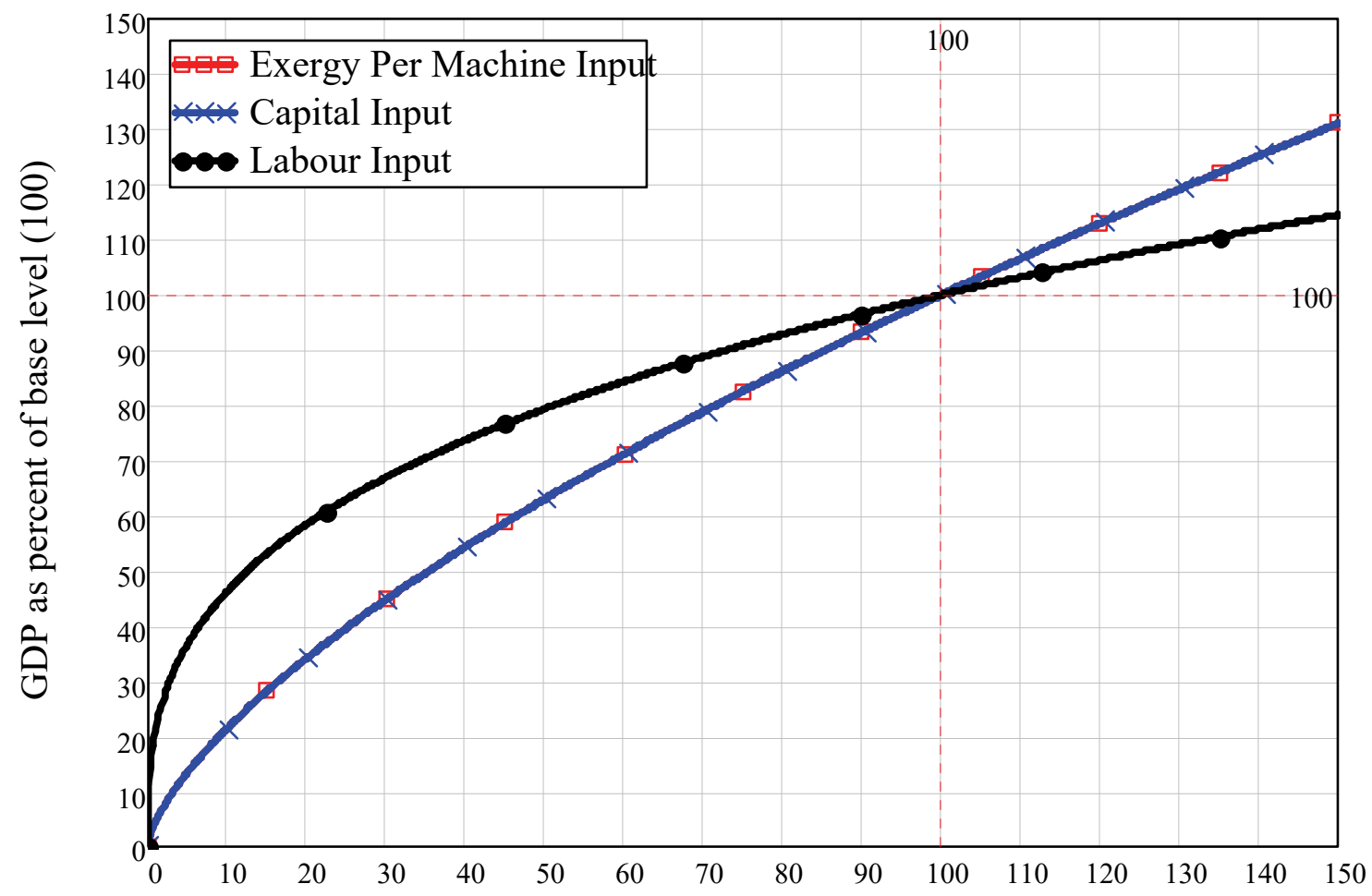

Percent of input compared to base level (100)

There is an additional issue not considered by Mankiw that can justify a higher value for $\alpha$. In the standard Cobb-Douglas Production function, A represents "total factor productivity", which is fitted to the data independently of both K and L. However, since we have shown in Equations (1.19) and (1.20) that $A$ is properly interpreted as the exergy per machine, a high value for $\alpha$ could potentially result from fitting Equation (1.23) to data:

$$
Q=C \cdot\left(E_{x}^{\Sigma K}\right)^{\alpha} \cdot L^{\beta}
$$

This is a topic for future research.

\section{Conclusion}

The epistemologically realistic introduction of energy into the Cobb-Douglas Production Function both solves and creates a number of conundrums. Firstly, it provides a production function in which energy plays an essential role: if the exponent for exergy in Equation (1.19) is set to zero, then so is the exponent for capital and the equation reduces to a crude labour theory of value.

Secondly, the equation is compatible with the Laws of Thermodynamics, since it reinterprets production as using energy to generate useful work, and the gap between the energy used in production and the useful work generated as GDP $\left(1-e_{X}{ }^{G D P}\right) \cdot E^{G D P}$ represents the waste energy necessarily generated by production. 
Thirdly, the "Solow Residual" is identified as the contribution of exergy to production. This could also justify a much higher value for $\alpha$ than in the standard CDPF, as suggested by Mankiw, though whether this is actually the case will depend on empirical research.

Finally, given the near linearity that applies to capital and exergy inputs in Equation (1.22), and the secondary role of labour in general in our energy-based approach, other production equations, such as the Leontief, that have no substitutability should also be considered, though these too need to be modified to properly incorporate the role of energy in production.

Ayres, R. and V. Voudouris (2014). "The economic growth enigma: Capital, labour and useful energy?" Energy Policy 64: 16-28.

Ayres, R. U., L. W. Ayres and B. Warr (2003). "Exergy, power and work in the US economy, 19001998." Energy 44: 219-273.

Ayres, R. U. and B. Warr (2005). "Accounting for growth: the role of physical work." Structural Change and Economic Dynamics 16(2): 181-209.

Bergh, J. C. J. M. v. D. (2009). "The GDP paradox." Journal of Economic Psychology 30(2): 117-135. Cobb, C. W. and P. H. Douglas (1928). "A Theory of Production." The American Economic Review 18(1): 139-165.

Felipe, J. and F. G. Adams (2005). "“A Theory Of Production" The Estimation of the Cobb-Douglas Function: a Retrospective View." Eastern Economic Journal 31(3): 427-445.

Felipe, J. and J. S. L. McCombie (2007). "Is a Theory of Total Factor Productivity Really Needed?" Metroeconomica 58(1): 195-229.

Harcourt, G. C. (1972). Some Cambridge Controversies in the Theory of Capital. Cambridge, Cambridge University Press.

Kümmel, R., R. U. Ayres and D. Lindenberger (2010). "Thermodynamic laws, economic methods and the productive power of energy." Journal of Non-Equilibrium Thermodynamics 35: 145-179.

Mankiw, N. G., E. S. Phelps and P. M. Romer (1995). "The Growth of Nations." Brookings Papers on Economic Activity 1995: 1: 275-326.

McCombie, J. S. L. (2000). "The Solow Residual, Technical Change, and Aggregate Production Functions." Journal of Post Keynesian Economics 23(2): 267-297.

Pasinetti, L. L., F. M. Fisher, J. Felipe, J. S. L. McCombie and R. L. Greenfield (2003). "Cambridge Capital Controversies." The Journal of Economic Perspectives 17(4): 227-232.

Robinson, J. (1971). "The Measure of Capital: The End of the Controversy." Economic Journal 81(323): 597-602.

Samuelson, P. A. (1966). "A Summing Up." Quarterly Journal of Economics 80(4): 568-583.

Santos, J., T. Domingos, T. Sousa and M. St. Aubyn (2018). "Useful Exergy Is Key in Obtaining Plausible Aggregate Production Functions and Recognizing the Role of Energy in Economic Growth: Portugal 1960-2009." Ecological Economics 148: 103-120.

Shaikh, A. (1974). "Laws of Production and Laws of Algebra: The Humbug Production Function." Review of Economics and Statistics 56(1): 115-120.

Shaikh, A. (1987). Humbug production function. The New Palgrave: A Dictionary of Economics. J. Eatwell, M. Milgate and P. Newman, Palgrave Macmillan.

Smil, V. (2017). Energy and Civilization: A History. Cambridge, MA, The MIT Press.

Solow, R. M. (1974). "Intergenerational Equity and Exhaustible Resources." Review of Economic Studies 41(5): 29.

Solow, R. M. (2010). Building a Science of Economics for the Real World. House Committee on Science and Technology Subcommittee on Investigations and Oversight. Washington.

Sraffa, P. (1960). Production of commodities by means of commodities: prelude to a critique of economic theory. Cambridge, Cambridge University Press. 
Stiglitz, J. E. (1974). "Growth with Exhaustible Natural Resources: The Competitive Economy." Review of Economic Studies 41(5): 139.

Warr, B., R. Ayres, N. Eisenmenger, F. Krausmann and H. Schandl (2010). "Energy use and economic development: A comparative analysis of useful work supply in Austria, Japan, the United Kingdom and the US during 100years of economic growth." Ecological Economics 69(10): 1904-1917. 